This item was submitted to Loughborough's Research Repository by the author.

Items in Figshare are protected by copyright, with all rights reserved, unless otherwise indicated.

\title{
Understanding dust sources through remote sensing: making a case for CubeSats
}

PLEASE CITE THE PUBLISHED VERSION

https://doi.org/10.1016/j.jaridenv.2020.104335

PUBLISHER

Elsevier

VERSION

AM (Accepted Manuscript)

PUBLISHER STATEMENT

This paper was accepted for publication in the journal Journal of Arid Environments and the definitive published version is available at https://doi.org/10.1016/j.jaridenv.2020.104335

LICENCE

CC BY-NC-ND 4.0

\section{REPOSITORY RECORD}

Baddock, Matthew, Robert Bryant, Miguel Domínguez Acosta, and Thomas Gill. 2020. "Understanding Dust Sources Through Remote Sensing: Making a Case for Cubesats". Loughborough University. https://hdl.handle.net/2134/13034606.v1. 
$6 \quad{ }^{1}$ Geography and Environment, Loughborough University, Loughborough, LE11 3TU, UK

$7 \quad{ }^{2}$ Geography, University of Sheffield, Sheffield, S10 2TN, UK

8 3Ingenieria Civil y Ambiental, Universidad Autonoma de Ciudad Juarez, 450 N. Avenida del

9 Charro, Ciudad Juarez, Chihuahua, 32315, Mexico

$10{ }^{4}$ Geological Sciences, University of Texas at El Paso, 500 W. University Avenue, El Paso,

11 TX, 79968, USA

12 *Email: $\underline{\text { m.c.baddock@lboro.ac.uk }}$

\section{Understanding dust sources through remote sensing: making a case for CubeSats}

Matthew C. Baddock ${ }^{1 *}$, Robert G. Bryant ${ }^{2}$, Miguel Domínguez Acosta ${ }^{3}$ and Thomas E. Gill ${ }^{4}$

5

\section{ABSTRACT}

Dust sources have been revealed through remote sensing, first regionally by $\sim 1^{\circ}$ resolution sensors (TOMS), then at sub-basin scale by moderate-resolution sensors (MODIS). Sensors with higher spatial resolution until recently were poorly temporallyresolved, precluding their use for systematic investigations of sources. Now, "CubeSat" constellations with high-temporal-and-spatial-resolution sensors such as PlanetScope offer $\sim 3 \mathrm{~m}$ resolution and daily (to sub-daily) temporal resolution. We illustrate the spatio-temporal dust plume observation capabilities of CubeSat data 22 through a dust event case study, Bolson de los Muertos playa, Chihuahuan Desert, 23 Mexico. For the event, PlanetScope showed numerous discrete point sources, 24 revealing variability of surface erodibility and emission over $\sim 8 \%$ of a focus area at 25 time of capture. The unprecedented detail of PlanetScope imagery revealed plume 26 development where outer-playa sands and fluvial-deltaic inputs contact lacustrine 27 silts/clays, consistent with field-studies. PlanetScope's high fidelity improves spatial 
28 quantification and temporal constraint of source activity, and we assess the spatio29 temporal capabilities of CubeSat in context with other dust observation remote 30 sensing systems. Compared to previous satellite technologies, CubeSats bring better 31 potential to link remote sensing to field observations of emission. This leap forward in 32 the remote sensing of dust sources calls for the systematic analysis of CubeSat 33 imagery in source areas.

35 Keywords: mineral aerosol, PlanetScope, MODIS, Chihuahuan Desert, dust 36 emission, playa

\section{INTRODUCTION}

39 For a more comprehensive understanding of the mineral dust cycle, there is a 40 recognised need for improved spatio-temporal constraint on the sources of dust 41 emission and their dynamics (Zender et al., 2003; Bullard et al., 2011; Shao et al., 42 2011; Heinold et al., 2016). Many of the fundamental properties of dust that govern its 43 potential environmental impacts (i.e., particle size, mineral and chemical composition) 44 are influenced by the particular source area it is emitted from. Sources are thus the 45 'launch pads' of mineral dust, and represent the start of its atmospheric lifecycle. Field46 based observation of dust emission at source, however, is not straightforward, given

47 the often remote and harsh environments where sources occur, as well as the 48 dynamic and complex spatio-temporal nature of emission processes (Thomas and 49 Wiggs, 2008; Field et al., 2009; Bullard, 2010; Bryant, 2013).

\subsection{Remote sensing of dust sources: a brief review}

52 Remote sensing has long provided significant advances in understanding the spatial 53 distribution and temporal variability exhibited by contemporary dust sources. 54 Improvements in spatial fidelity of sensors have in particular provided an impetus for 55 interpreting the dust cycle and the nature of dust sources. The first multi-annual, global 56 remote sensing studies of atmospheric dust loading established the dominant large57 scale source regions, revealing the importance of closed hydrological basins 
58 (Prospero et al., 2002; Washington et al., 2003). Such basins were either inundated 59 during the Pleistocene and/or undergo ephemeral flooding in modern climates, storing 60 accumulated fines, the deflation of which makes them major sources (high frequency 61 and/or high magnitude emission) of mineral dust. The Total Ozone Mapping 62 Spectrometer (TOMS) provided landmark characterisation of dust sources in the early 632000 s at a spatial resolution of $\sim 1^{\circ}$ (Prospero et al., 2002; Washington et al., 2003).

64 Subsequent time-series observations of dust at this scale revealed the intermittency 65 and interannual variability of emission from key source regions, especially those 66 outside of the principal Saharan Dust Belt (Mahowald et al., 2003; Zender et al., 2003;

67 Bryant et al., 2007; Mahowald et al., 2010). Following the identification of major dust68 emitting basins, ensuing remote sensing investigations of source regions focused on 69 finer spatial scales, notably adopting a sub-basin scale of enquiry. This "drilling down" 70 was motivated by knowledge that while individual, often huge, basins were identifiable 71 as single large-scale entities, the actual locations of dust emission occurred at much 72 smaller spatial scales within them, preferentially linked to certain geomorphology and 73 surface types (Bullard et al., 2008; 2011).

75 Sub-basin focused studies were driven by improvements in sensor technology, 76 especially the early-2000s advent of the daily (later twice daily) $0.25-1 \mathrm{~km}$ resolution hyperspectral Moderate Resolution Imaging Spectroradiometer (MODIS) (Muhs et al., 78 2014). The spatial scale offered by MODIS allowed remote sensing studies to pick out the individual contributions, dynamics and chronologies of dust emission from the mosaic of geomorphic settings and surface types within large basins. MODIS' resolution proved highly appropriate for producing inventories of dust point sources within larger dust source regions (e.g. Bullard et al., 2008; Zhang et al., 2008; Lee et al., 2009, 2012; Walker et al., 2009; Baddock et al., 2011; Vickery et al., 2013; 84 Hahnenberger and Nicoll, 2014; Kandakji et al., 2020). The hyperspectral capacity of MODIS additionally allowed the development of a range of image processing algorithms (e.g. Ackerman, 1997; Miller, 2003; Murray et al., 2016; Yue et al., 2017)

87 and derived data products (e.g. 'Deep Blue Aerosol Optical Depth' (Hsu et al., 2013) 88 and 'Dust Optical Depth' (Ginoux et al., 2010)). These approaches have enhanced 
89 detection and quantification of suspended dust via its optical and physical properties,

90 and proved useful in the determination of emitting surfaces (e.g. Baddock et al., 2015;

91 Yue et al., 2017).

92

93 MODIS' spatial resolution in particular has contributed to quantifying and refining of 94 the idea that dust emission is spatially-localized, displaying a 'hotspot' nature, from 95 preferential source areas within a broader landscape (Gillette, 1999). Remote sensing 96 at the sub-basin scale has revealed long term connections between hydrology and 97 geomorphology (both controlling sediment supply and availability), and allowed quantification of different surfaces' potential for dust emission (Kocurek and

99 Lancaster, 1999; Bullard et al., 2011). A frequent goal of the sub-basin, MODIS-led 100 studies has been to understand spatial variations in dust emissivity to better represent surfaces in models, toward improved estimates of predicted emission (Zender et al., 2003; Bullard et al., 2011; Parajuli et al., 2014; Baddock et al., 2016; Parajuli and 103 Zender, 2017).

1.2 New opportunities for observing dust emission at the sub-basin scale

106 The scale at which MODIS provides insights for characterising preferential dust 107 sources is exemplified in Figure 1. The Chihuahuan Desert of North America was 108 broadly identified as a dust source region by TOMS-based global surveys (Prospero 109 et al., 2002), and subsequently, moderate resolution data (AVHRR, Advanced Very 110 High Resolution Radiometer, Rivera Rivera et al., 2010; MODIS, Baddock et al., 2011; 111 2016) were applied to elucidate the patterns of dust emission at a sub-basin scale. 112 For instance, in the northern Chihuahuan Desert, both the long term distribution of 113 dust-related satellite data products (processed to $10 \mathrm{~km}$ resolution) (Figure 1a) and 114 multi-annual dust event plume analysis (Figure 1b,c) from MODIS have characterised 115 the linkages between dust emission and surface geomorphology in the region. These 116 approaches have highlighted the significance of ephemeral lake and low-relief alluvial 117 systems as preferential sources. 
119 Despite insights provided by moderate resolution sensors, the scale of these data 120 means that processes driving dust uplift, operating as surface-boundary layer 121 interactions, can only be inferred (Webb and Strong, 2011). At the level of detail 122 provided by moderate resolution imagers, the heterogeneity in remotely sensed dust 123 observations is largely a product of sensor spatial resolution. It therefore remains 124 difficult to reconcile this resolution with field-based in situ investigations of emission 125 which have revealed sub-MODIS-scale variations between eroding and non-eroding 126 surfaces (Lee et al., 2009; Bryant, 2013; Sweeney et al., 2011; von Holdt et al., 2019; 127 Cui et al., 2019).

128 In Earth observation for environmental monitoring, fundamental trade-offs exist 129 between spatial and temporal resolutions in the repeat viewing of fixed locations 130 (Cooley et al., 2017). Single platforms with sensors that achieve relatively high 131 resolution surface imaging are usually associated with longer intervals between repeat 132 coverage, such that their sampling prevents frequent observation of dust source 133 activity (e.g. Landsat 8 at $0.03 \mathrm{~km}$ offering 16 day repeat in sub-tropical regions). 134 Sensor technologies with off-nadir capabilities such as Satellite Pour l'Observation de 135 la Terre (SPOT; revisit of 1-3 days in this mode) are often utilised for faster emergency 136 response (e.g. Lui and Hodgson, 2016), but are not currently widely available nor 137 archived with global coverage (d'Angelo et al., 2016). The critical importance of 138 temporal sampling explains why daily-to-sub-daily observations from MODIS, and the 139 even higher frequency data capture of the Spinning Enhanced Visible and Infrared 140 instrument (SEVIRI) onboard the geostationary Meteosat Second Generation 141 platform, have proved especially valuable in recording variations in global (Ginoux et 142 al., 2012) and regional dust activity (Schepanski et al., 2007, 2009, 2012; Walker et 143 al., 2009; Ashpole and Washington, 2013; Murray et al., 2016; Hennen et al., 2019), 144 across moderate/coarse ground resolutions $(0.25-10 \mathrm{~km})$. New geostationary satellite 145 platforms such as Himawari and GOES-R ( 10 min sample time) have significantly 146 improved dust source detection in regions beyond the Sahara (She et al., 2018; 147 Kondragunta et al., 2018). However, the coarse spatial resolution ( $2 \mathrm{~km})$ of these 
148 sensors is insufficient for pinpointing local sources and detailed observation of dust 149 emission processes (Sowden et al., 2018). Clearly, spatial resolution remains a key 150 constraint for remotely observing, characterising and quantifying dust source 151 behaviour.

152 Where Landsat is a single platform, and MODIS monitors from two satellite platforms 153 (Terra and Aqua, with VIIRS (Visible Infrared Imaging Radiometer Suite) as a 154 comparable afternoon follow-on), recent developments have led to development of 155 miniaturised, multi-platform satellite constellations (e.g. da Silva Curiel et al., 2005) 156 now often referred to as "CubeSats" or "NanoSats". With these constellations, 157 extremely high spatial resolution $(0.003-0.005 \mathrm{~km})$ Earth observation is now 158 achievable on a daily or better basis, through coverage achieved by the large number 159 of platforms (Plekhov and Levine, 2018). CubeSat and NanoSat deployment has 160 moved rapidly in Earth observation over the last five years (e.g. Villela et al., 2018; 161 Crusan and Galica, 2019) and Planet Lab's suite of Dove satellites equipped with the 162 PlanetScope sensor is one such novel constellation. Systematic interrogation of its 163 finely-resolved spatial data now can provide insights into dust sources at very high 164 resolution $(0.002-0.005 \mathrm{~km})$. Given the number of satellites in the PlanetScope 165 constellation, depending on orbits, multiple images can be available for the same 166 location for a given day, providing potential sub-daily, optimally sub-hourly, imaging 167 capability (Plekhov and Levine, 2018). The short ( $<24 \mathrm{~h})$ turnover between 168 PlanetScope data capture and availability for download and processing is an added 169 benefit for dust monitoring, analogous to the near real-time availability of MODIS data.

170 At time of submission, >100 3U CubeSat/Dove platforms (assigned via constellation 171 Flocks; Kopacz et al., 2020) were in orbit, each mounted with the PlanetScope 172 instrument (Planet Labs, 2020), imaging in four bands (Red, Green, Blue, Near173 Infrared) with an orthorectified spatial resolution of $\sim 3 \mathrm{~m}$. Regular data from these 174 satellites became available in early 2017, and with its frequent delivery of very high 175 spatial resolution imagery, PlanetScope has been applied in a range of dynamic 176 surface change studies (e.g. Cooley et al., 2017; Wikacsono and Lazuardi, 2018: Park 177 et al., 2019). Given the progress achieved through improved sensor resolution, 
178 application of PlanetScope to observing dust sources represents a next step in remote 179 sensing of mineral dust emission.

180 An inherent trade-off in sensor miniaturisation and payload optimisation for systems 181 like PlanetScope, however, concerns the wavelengths sampled, such that 182 PlanetScope provides only four proprietary wavebands. This relatively narrow spectral 183 resolution reduces the opportunities for optimising dust detection afforded by a wider 184 sampled spectral range, and in this paper, simple true-colour scenes are inspected. 185 Despite an absence of multispectral dust enhancement procedures, and issues of 186 subjectivity or inaccuracy in point mapping (Baddock et al., 2009; Walker et al., 2009; 187 Sinclair and Legrand, 2019), identifying dust plume origin points with true-colour 188 imagery is an established means of mapping actively emitting portions of surfaces 189 (e.g. Eckardt and Kuring, 2005; Lee et al., 2009; Hahnenberger and Nicoll, 2014; 190 O'Loingsigh et al., 2015; Li et al., 2018; Nicoll et al., 2020). PlanetScope data are 191 clearly well-suited for this purpose.

Herein we demonstrate the potential for understanding dust source characteristics that comes from enhanced satellite spatial resolution, specifically that provided by 196 PlanetScope. We then go on to consider the place of these new data for improved characterisation of dust source dynamics. Our demonstration is used to consider how the capabilities of CubeSats and sensors like PlanetScope occupy a valuable niche in terms of the temporal and spatial constraints limiting remote sensing systems currently applied to dust observation. In a proof-of-concept study, we illustrate the performance of PlanetScope during a dust event occurring in one of North America's most persistent dust sources, presenting this in the wider context of insights that moderate resolution remote sensing provides for source areas in the region. We demonstrate

204 the fact that PlanetScope now offers a spatial fidelity that improves remote detection 205 of dust emission, and can closely augment field-scale observations of dust. 


\subsection{Study location}

209 To demonstrate the potential of high resolution imagery, an example from the northern

210 Chihuahuan Desert is employed. The atmospheric dust loading from the Chihuahuan

211 Desert and the region's importance for aeolian processes in the Western Hemisphere 212 emerged in global remote sensing dust studies (Prospero et al., 2002; Ginoux et al., 213 2012). Further regionally specific studies have helped elucidate the erosivity and 214 erodibility-related controls governing the dust activity (e.g. Lee et al., 2009; Rivera 215 Rivera et al., 2010; Floyd and Gill, 2011; Baddock et al., 2011, 2016; Klose et al., 216 2019) (Figure 1).

218 We focus on the Paleolake Palomas (PLP) basin, an extensive Pleistocene pluvial 219 lake system spanning the present-day boundaries of Chihuahua (Mexico) and New 220 Mexico (USA), which covered $\sim 7700 \mathrm{~km}^{2}$ at maximum extent (Dominguez Acosta, 221 2009). The basin now exists as a series of interconnected ephemerally-inundated 222 playas (Castiglia and Fawcett, 2006) which serve as dust emission hotspots 223 (Dominguez Acosta, 2009; Rivera Rivera et al., 2010; Baddock et al., 2011, 2016). 224 The largest and southernmost of these playas, Bolson de los Muertos (BdIM), extends 225 approximately $90 \mathrm{~km}$ north-south and up to $25 \mathrm{~km}$ east-west at its widest point. The 226 BdIM consists of a wide central "body" with two "arms" (lobes) extending to the 227 southwest and southeast (Figure 1c). Each lobe is associated with an inputting river 228 system that no longer enters the BdIM under contemporary conditions but was 229 connected during late Pleistocene wet periods (Rio Santa Maria entering the SW lobe 230 and Rio del Carmen the SE lobe) (Dominguez Acosta, 2009). Historical fluvial inputs 231 associated with the discharge of the Rio Santa Maria into the SW lobe led to the 232 deposition of deltaic sediments in portions of the playa (marked on Figure 1c).

234 While lacking regular fluvial inflow in the present climate, the two individual lobes 235 occasionally demonstrate "wet playa" behaviour (Rosen, 1994) associated with their 236 status as regional topographical sinks. Acting as small endorheic basins, the lobes 237 periodically accumulate water from major regional precipitation events, receiving in- 
238 washed alluvial sediment from surrounding higher elevations. This hydrological and 239 sediment recharge behaviour modulates the lobes' activity as sources of dust, but 240 contributes to the overall highly emissive nature of these playa surfaces in the longer 241 term (Reynolds et al., 2007) (Figure 1a,b).

243 For this case study, we consider the southwestern arm of the BdIM (SW BdIM), 244 elongating approximately $30 \mathrm{~km}$ in a NNE direction and $9 \mathrm{~km}$ wide. The inner part of 245 the SW BdIM is generally unvegetated, flat, devoid of non-erodible elements, and filled 246 with fine (silty clay) clastic sediments, covered after evaporation of late summer 247 monsoon moisture by a thin clay crust. Surrounding this inner core of playa sediments 248 is a sparsely-vegetated (a few patches of grasses) marginal sand sheet augmented 249 with fluvial-deltaic sediments to the northwest, deposited by the paleo-inflows of the 250 Rio Santa Maria, and Quaternary alluvial deposits on the west, shed from the Cerros 251 la Nopalera. These fluvial and alluvial sediments accumulated on the western and 252 northern SW BdIM playa surfaces as graded beds ranging from clay and silts to small 253 amounts of sand-sized sediments and some deltaic rounded gravels (Dominguez 254 Acosta, 2009). Land use is very sparse and primarily livestock grazing, although 255 irrigated cropland agriculture is practiced in isolated areas adjoining the BdIM and 256 more widely in the floodplain of the modern Rio Santa Maria upstream. There is 257 minimal land use of the playa surface itself.

259 The combination of strong westerly/southwesterly winds (perpendicular to the 260 orientation of the PLP basin) during the dry season, and sands on the upwind outer 261 margin of the playa that saltate onto the fine sediments in the playa's centre, leads to 262 frequent emission of dust plumes from the BdIM. Such events are regularly identifiable 263 on MODIS imagery (Lee et al., 2009; Rivera Rivera et al., 2010; Baddock et al., 2011) 264 (Figure 1b,c). Dust plumes from the BdIM, other sub-basins of PLP, and other sources 265 regularly merge into regional-scale dust events which cause air quality hazards to the 266 Ciudad Juarez (Chihuahua)-El Paso (Texas) metropolitan area (Rivera Rivera et al., 267 2010; Rivas et al., 2019) and can extend at least $800 \mathrm{~km}$ downwind across Texas (Lee 268 et al., 2009). 
270 Previous research has examined Chihuahuan Desert dust sources at a sub-basin 271 scale, using the Preferential Dust Source (PDS) classification scheme (Baddock et 272 al., 2011; Bullard et al., 2011). PDS was designed to represent observations that dust273 yielding basins are comprised of different geomorphology or surface types, each with 274 varying potentials to emit dust. The PDS surface classification effort was intended to 275 understand the influence of variations in surfaces and their sediments on dust activity 276 at a sub-basin scale (Bullard et al., 2011). The PDS scheme was applied to the 277 Chihuahuan Desert (e.g. Figure 1b), and is explained, by Baddock et al. (2011), who 278 mapped attribution of PDS geomorphological classes to polygons of the Mexican 279 national land type mapping system ("Sistema de Topoformas") as distributed by the 280 national geospatial agency (INEGI, 2001). For the smaller scale of the current SW 281 BdIM study, it was possible to use the more detailed national soil map polygons 282 provided by INEGI (2001).

284 To help formalise the analysis of the dust event, a regular grid of $100 \mathrm{~m}^{2}$ cells was 285 generated over the polygon from the PDS scheme representing the entire BdIM 286 (Figure 1c). While application of this $100 \mathrm{~m}$ scale grid is somewhat arbitrary, in their 287 review of wind erosion modelling, Webb and Strong (2011) propose the scale between 288 what they term 'plot' $\left(10^{1}\right)$ and 'landscape' $\left(10^{3}\right)$ as the appropriate scale at which to 289 consider emission processes. Analysing these $100 \mathrm{~m}$ cells is an appropriate scale to 290 map emission detectable in ( $\sim 3 \mathrm{~m}$ resolution) PlanetScope imagery.

\subsection{Study dust event and satellite imagery}

293 To illustrate a dust event detected via high resolution PlanetScope in the context of 294 moderately resolved MODIS data for the region (Figure 1), dust emission occurring at 295 the SW BdIM was chosen from 30th November 2018. On this day, a strong Pacific 296 cold front, aligned with an upper-level trough and extending southwestward from a 297 cyclone centred in northeast New Mexico, crossed the northern Chihuahuan Desert 298 from west to east. This produces an ideal synoptic weather pattern for dust storms in 299 the region (Rivera Rivera et al., 2009). Winds gusted to $90 \mathrm{~km} / \mathrm{h}$ at El Paso 
300 International Airport, $\sim 140 \mathrm{~km}$ north-northeast of the SW BdIM; hourly PM10 301 concentration recorded by the Texas Commission on Environmental Quality at 302 Socorro (southeast of El Paso and $\sim 130 \mathrm{~km}$ northeast of the SW BdIM) reached 961 $303 \mu \mathrm{g} / \mathrm{m}^{3}$ while hourly $\mathrm{PM}_{2.5}$ concentration reached $62 \mu \mathrm{g} / \mathrm{m}^{3}$, both at $0900 \mathrm{MST}$ (1600 304 UTC).

Imagery for the event was obtained from the Planet Labs exploration portal (www.planet.com) and the NASA Worldview site for pre-processed MODIS data. We examine true-colour imagery of SW BdIM from PlanetScope (1706 UTC capture time), and MODIS Terra (1735 UTC) and Aqua (2050 UTC). For PlanetScope, bands 1-3 (Blue: $455-515 \mathrm{~nm}$, Green: 500-590, Red: 590-670 nm) of the Level 3B Analytic Ortho Scene Product in GeoTIFF format were obtained and composited to produce simple true-colour scenes. Two scenes from 1706 UTC imaged along the same sensor overpass (37 and 38 seconds past the minute) were used in a mosaic over the SW BdIM study area.

\section{RESULTS}

A broad view of the 30th November 2018 BdIM dust event is shown by the Terra and Aqua MODIS scenes (Figure 2a,b). MODIS imagery quality for the event is relatively poor, due to inherent problems of native resolution (WorldView imagery resampled to $250 \mathrm{~m}$ ) and pixel stretch near the edge of the image swath, but the MODIS true-colour data reveal dust in a part of the playa known to emit often. In the Aqua scene, an elevated plume is most clearly visible heading eastward, showing a typical dust uplift pattern with the passage of a Pacific cold front (cf. Figure 1c). A best-estimate of the upwind point of the plumes identifies active emission in the SW BdIM, which the long 326

327 PlanetScope overpasses covering the event were available from $\sim 30$ minutes before 328 the Terra overpass. Analysis of the PlanetScope data reveals numerous discrete, identifiable dust plumes in the SW BdIM, whose upwind extent can be tracked to specific emitting parts of the playa surface (Figure 2c [A high resolution image of this 
331 figure panel is available in the Supplementary Material]). Directly comparing the best 332 interpretation of the true-colour MODIS and PlanetScope scenes, the MODIS points 333 coincide fairly well with the most well-developed coalesced plumes shown on 334 PlanetScope, $<2 \mathrm{~km}$ of their apparent upwind origins (Figure 2d). Crucially however, 335 many more smaller plumes are identifiable via PlanetScope from multiple parts of the 336 playa, providing much more detail and accuracy concerning the specific parts of the 337 surface that are emitting.

339 When applied to the regular $100 \mathrm{~m}^{2}$ grid placed over the BdIM, those grid cells where 340 emission and plume initiation could unambiguously be identified at the upwind edge 341 of the lofted plumes are highlighted (Figure 2d). The area of focus indicated in Figure $3422 \mathrm{a}, \mathrm{b}$ represents an approximately $8.25 \mathrm{~km}$ square section $\left(68.3 \mathrm{~km}^{2}\right)$. Image 343 interpretation indicates that 68 cells contained the onset of plumes at the upwind 344 boundaries of emission (Figure $2 \mathrm{~d}$ ), equating to $\sim 1 \%$ of the focus area. MODIS-based 345 studies have identified a significant bias in favour of identification of upwind source 346 points in point inventories (e.g. Lee et al., 2009; 2012; also SEVIRI, Hennen et al., 347 2019), due to the inability to detect discrete points invisible underneath the main 348 plume. This limitation largely restricts determination of source points to those at the 349 upwind "plume heads" (Walker et al., 2009; Sinclair and Legrand, 2019). Whilst also 350 an issue for interpretation of the PlanetScope imagery, the increased level of detail 351 from PlanetScope offers increased ability to ascertain those surfaces that are actively 352 emitting downwind from the upwind boundary of emission. In Figure 2d, additional 353 cells estimated as being highly likely to contain emission, as evidenced by the 354 presence of multiple plumes appearing close to the surface, and downwind of 355 discernible upwind initiation, are also indicated. These additional 499 cells account for 356 a further $\sim 7.3 \%$ of the area, indicating evidence of dust emission occurring in total 357 over $\sim 8 \%$ of the focus portion of SW BdIM. 
362 Here, in showing PlanetScope imagery over a source area during a dust emission 363 event, we demonstrate how its high resolution allows direct observation of active 364 plume development to an unprecedented degree. That the imagery allows pinpointing 365 of the upwind origin of individual dust plumes to precise emission surfaces and small366 scale geomorphic setting emphasises the detail of emission processes that can be 367 unlocked from these high resolution images. This capability achieves insights into the 368 spatial heterogeneity of processes and emission far beyond that revealed by moderate 369 resolution sensing (Figure 1; Figure 2).

371 For instance, PlanetScope reveals that the cluster of dust plumes initiating from the 372 outer northwest portion of the BdIM focus area (Figure 2c,d) is located in a zone where 373 numerous small washes terminate, indicating where sediments of mixed sizes from 374 the Rio Santa Maria paleodelta are likely to have been brought onto the playa. This 375 line of washes and presence of fluvial material extends to the northeast, with the 376 distribution of active dust emission grid cells also stretched in that direction. This 377 location is also consistent with areas where playa-marginal sands, undergoing 378 saltation by W-WSW wind, would move onto lacustrine clays dominating the inner 379 playa surface. Such contact zones in playa basins are well known to become 380 preferential dust sources due to the combination of loose sands for saltation 381 bombardment over fine sediments (Cahill et al., 1996; Gill, 1996; Lee et al., 2009; 382 Rivera Rivera et al., 2010; Bullard et al., 2011).

384 The multiple dust plumes in the central part of the playa shown by PlanetScope, close 385 to the source point evident from Aqua MODIS, also reveal emission occurring further 386 from the edges and availability of aeolian or fluvial inputs, which potentially reflects 387 the action of other emission drivers (Figure 2d). Dust emission here may be 388 associated with areas of weakly-crusted playa surface, susceptible to breakage and 389 auto-erosion, exposing unconsolidated silt-clay sediments underneath to the wind, as 390 documented on other parts of the BdIM (Dominguez Acosta, 2009) and at Owens Lake 391 (Cahill et al., 1996). The most southerly cluster of dust plumes revealed by 
392 PlanetScope in the scene is again consistent with W-WSW winds entraining sand 393 sheet sediments from the upwind outer playa, bringing them into contact with finer 394 lacustrine clays and silts, to drive dust emission. In addition, the long fetch in the 395 direction of wind run across the flat playa likely contributes to a high potential for 396 emission from erodible surfaces downwind (Cahill et al., 1996; Gillette, 1999). Clearly, 397 the detail in which aeolian processes can be interpreted from PlanetScope is much 398 improved over the equivalent MODIS data. Although Figure $2 \mathrm{~d}$ indicates broad spatial 399 agreement between the MODIS-estimated plume origins and the pinpoint distribution 400 from PlanetScope, an enhanced ability to interpret processes stems from improved 401 accuracy in determination of emission points in high resolution data (Sinclair and 402 Legrand, 2019). In source identification studies led by moderate resolution sensors 403 with daily sampling rate, uncertainty can exist whether the upwind edge of a plume is 404 associated with active emission at the time of capture (Schepanski et al., 2007; 2009). 405 Here, when PlanetScope overpass clearly occurs some time after the onset of 406 emission, the detail of scene resolution allows plumes to be unambiguously traced 407 back to ongoing, active emission (Figure 2c).

409 A comparable dust-free scene of the SW BdIM from a few days before the study event, 410 is valuable for characterising contemporary surface state, and its temporal change, in 411 a system such as a playa (Figure 3) (Reynolds et al., 2007; Urban et al., 2018). For 412 instance, PlanetScope detail in the dust-free image is sufficient to identify large 413 polygon-shaped desiccation peds (characteristic of the BdIM in general (Dominguez 414 Acosta, 2009)), indicating the high clay and silt concentrations, and surfaces 415 previously inundated by water. Figure 3 also specifically indicates dust was not 416 emitted from the central portion of the focus area, where the surface appears visibly 417 darker. This darker surface indicates the presence of vegetation at the time, as 418 evidenced by comparison of vegetated channels and arroyos seen off the playa, most 419 notably to the west. Where vegetation likely to be of remnant state acts as non420 erodible cover on the central portion of the playa saltation bombardment will be 421 impeded (Lancaster and Baas, 1998), thus limiting plume development. Inspection of 422 the dust-free imagery helps to account for this control on emission. 
425 In summary, the detail provided by the PlanetScope imaging of plume sources 426 reinforces the broader importance for dust emission of contacts between different 427 geomorphic domains. In this case, the known connectivity between saltator availability 428 at playa margins, fluvially-provided wind-suspendible fines, and lacustrine sediment 429 of variably crusted state is emphasised for the first time in satellite imagery. These 430 and other linkages can be determined by interpretating the locations where emission 431 points can be unambiguously pinpointed (Mahowald et al., 2003; Lee et al., 2009; 432 Bullard et al., 2011; Klose et al., 2019).

4.2 Scale limits for dust source monitoring using PlanetScope data

435 In order to understand dust emission processes, one of the key challenges has been 436 to match remote sensing observations to the space and time scales of field-observed 437 emission (Bullard, 2010; Bryant, 2013). The BdIM dust source observations in our 438 case study enable reflection on the relative contribution of remote sensing data to both 439 dust source and dust plume detection, and how these relate to improved 440 understanding of emission. The relative scales at which commonly used remote 441 sensing data are able to characterise dust emission events are summarised in Figure 442 4. When considering these, a number of studies acknowledge the small scale and 443 stochastic nature of the dust emission process (e.g. Gillette, 1999; Lee et al., 2009; 444 Bullard et al., 2011; Shao et al., 2011; Kok et al., 2014). Field and modelling studies 445 in and around playa basins (e.g. Cahill et al., 1996; King et al., 2011; Sweeney et al., 446 2011; von Holdt et al., 2019) have highlighted the variability of surface erodibility and 447 the importance of crusts for the dust emission process. Haustein et al. (2015) go one 448 step further, matching the scale of emission to dust modelling schemes, highlighting 449 how surface heterogeneity can lead to significant uncertainty in model estimates. 450 Using the most informative studies in terms of the spatial scale of emissions, such as 451 Webb and Strong (2011) and Haustein et al. (2015) as a baseline, we infer an 452 approximate "scale limit" (c. $10^{2} \mathrm{~m}$ and $<1$ day) for dust source detection that is able 453 to capture site information appropriate to the scale of surface erodibility heterogeneity. 
454 This is the scale that can be complementary to in situ observation of emission. For 455 understanding the contribution of remote sensing, this "scale limit" therefore 456 represents an arbitrary divider between remote sensing detection of dust emissions 457 observed at the field-scale (thereby linked to process), and dust plumes evident at the 458 basin and sub-basin scale (from which we must infer process). Temporally, it is clear 459 that observations captured sub-daily are also essential to establish the locations of 460 dust emission (Schepanski et al., 2009; Shao et al., 2011; Webb et al., 2019; Klose et 461 al., 2019); such observations are possible with the PlanetScope data (Figure 5).

Webb and Strong (2011) provide a robust framework for the spatial and temporal scales at which dust emission and transport operate. A summary of how these processes are sampled by remote sensing data types is provided in Figure 4, and we use our emission scale limit to consider the likely detection of dust in transport, or, dust emission at source. In terms of temporal resolution, we note that the frequency of dust event detection (e.g. as observed from synoptic weather code reports at WMO 472 sites; O'Loingsigh et al., 2010) increases significantly at a sub-day frequency (e.g. 473 Novlan et al. (2007) for the northern Chihuahuan Desert). Figure 4 shows that most 474 current dust remote sensing applications work outside the required lower scale limit. 475 Initial source detection efforts using TOMS (e.g. Prospero et al., 2002; Figure 4, A) 476 were only able to identify candidate basin-scale dust sources and subsequently relate 477 the dynamics of these to regional climate and landscape scale processes (e.g. Bryant 478 et al., 2007). At a basin and sub-basin scale, geostationary satellites (e.g. SEVIRI: 479 Schmetz et al., 2002; Himawari: Bessho et al., 2016) have been used to detect, track 480 and characterise dust emissions over large regions (e.g. Schepanski et al., 2009; 481 Banks and Brindley, 2013; Figure 4, B). In practice, these data have been used to (i) 482 detect and build inventories of dust events used to infer source regions (e.g. Hennen 483 et al., 2019), (ii) match events to synchronous data to determine climatological drivers 484 of emission over short (<day) to decadal timescales (e.g. Schepanski et al., 2009; 
485 Gasch et al., 2017), and (iii) provide quantitative estimates of dust properties and 486 radiative impacts (e.g. Brindley et al., 2012). Where these data have been used to 487 detect and identify dust events at the sub-basin scale (e.g. Murray et al., 2016; Hennen 488 et al., 2019) they are often only able to track clearly visible plumes locations to within 489 3-8 km of likely source location, making links between plot-scale emission processes 490 and dust events difficult to resolve (Figure 4, B).

492 Data from moderate resolution sensors (e.g. MODIS, VIIRS; Figure 4, C), have also 493 been used extensively to observe plumes close to dust sources either involving 494 subjective analyses (e.g. Bullard et al., 2008; Baddock et al., 2009; Lee et al., 2009; 495 2012) or the use of processed, dust-related data products (e.g. Ginoux et al., 2010; 496 2012; Baddock et al., 2016). The increased spatial resolution of MODIS-like data 497 produces a shift towards the suggested scale limit, thereby enhancing characterisation

498 of dust emission hot spots and their candidate geomorphic settings. Synergistic use 499 of data from these moderate resolution sensors has also increased our understanding 500 of dust sources and transport corridors (e.g. Bakker et al., 2019). As an Earth 501 monitoring system, the combination of Sentinel 2A/B and Landsat 8 (Figure 4, D) 502 offers the ability to determine dust emission at a scale which may approach the 503 required scale limit. The image resolution and image scene size of these data certainly 504 facilitate dust plume interpretation at the sub-basin and landform scale (e.g. von Holdt 505 et al., 2017; 2019), however, the best combined revisit period for these data for most 506 areas (c. 5 days) still falls below that required to capture dust emission data sufficiently 507 regularly to usefully match field observations (e.g. Li and Roy, 2017). In our case 508 study, we show the relative advance that PlanetScope data, and CubeSat509 constellation observation systems in general, can make through high spatial and 510 temporal observation of dust source dynamics, operating inside the suggested 511 space/time scale limits for plot-scale monitoring proposed here (Figure 4, E).

5134.3 Benefits of dust emission monitoring via CubeSats

514 The analysis provided in Figure 2 indicates how future in-depth studies might 515 characterise specific emission locations with greater space/time fidelity than can 
516 moderate resolution sensors, and thereby may better inform representation of surface 517 types within dust emission models. Dust emission characterisation through 518 PlanetScope's high resolution imagery is clearly relevant to the small scale 519 parameterisations required to improve large-scale dust modelling (Thomas and 520 Wiggs, 2008; Bullard, 2010). Within an area of land surface known to be highly 521 emissive, in this example $<10 \%$ of the surface was assessed to be unambiguously 522 emitting at one time during the study dust event (Figure 2d). At the scale of the PDS 523 classification, the whole of BdIM is uniformly classified as "ephemeral playa" (class

524 1b; Bullard et al., 2011). PlanetScope, however, establishes the actual spatial 525 variability of emission within this single MODIS-scale surface class, helping to account 526 for variability in emission potential observable in the field (e.g. von Holdt et al., 2019; 527 Klose et al., 2019; Cui et al., 2019).

529 Another key benefit of high resolution monitoring of aeolian processes is an improved 530 ability to constrain timing of dust uplift and the role of small-scale meteorological 531 processes in dust emission, approaching comparability with field-based observations 532 (Figure 5). The contribution of high temporal frequency remote sensing in this regard 533 has been demonstrated for SEVIRI (e.g. Schepanski et al., 2009). Future studies that 534 couple high spatial resolution imaging with high temporal resolution ground-based 535 measurement of key meteorological variables (the latter primarily related to 536 determining transport capacity i.e. shear velocity, turbulent gusting etc.), will combine 537 "top down" and "bottom up" perspectives of dust emission (Richter and Gill, 2018) with 538 better fidelity. Detailed ground observation studies such as the intensive remote 539 camera-based dust monitoring of Soda Lake, a Mojave Desert playa, by Urban et al. 540 (2018), are one way to evaluate the level of dust activity that PlanetScope can 541 additionally retrieve.

543 Aside from the transport capacity-limitation (wind threshold exceedance), dust uplift in 544 most global dust source areas is also limited by two other factors; (i) sediment 545 availability, and/or (ii) sediment supply (Kocurek and Lancaster, 1999; Bullard et al., 
546 2011). When considering the sediment availability-limitation, the temporary flooding 547 of a surface, such as the BdIM playa, often followed by vegetation growth and/or 548 development of surface crusting, leads to dust-sized sediment not being available to 549 erode. After drying or crust weakening, this availability-limitation becomes relaxed, 550 and sources may emit again (Mahowald et al., 2003; Bryant et al., 2007). Periodic 551 'switching off-switching on' of dust emission is a fundamental aspect of variability in 552 dust source activity, and must be accounted for in the accurate simulation of regional 553 dust regimes. Detailed imagery such as from PlanetScope will enable daily monitoring 554 of emissions from specific surfaces, revealing both when and where they begin to be 555 emissive, and crucially, when and where they do not. While timing of overpasses will 556 remain an issue for capture of emission, the repeat spatial resolution of CubeSats can 557 nevertheless better establish controls on (i) geomorphic thresholds of emission, and 558 (ii) temporal constraints on dust uplift. In the latter case, linkage of pinpoint emission 559 observation to key meteorological parameters, including in situ measurements where 560 possible (e.g. Haustein et al., 2015), and to hydrological histories of the location 561 (inundation and drought regime), can help validate dust modelling efforts.

563 Finally, we suggest how the unprecedented detail of CubeSat data can guide enquiry 564 into dust emission for both future remote sensing technologies and field observations. 565 For instance, one important contribution will be the opportunity to help target remote 566 sensing missions such as the Earth Surface Mineral Dust Source Investigation (EMIT; 567 Thompson et al., 2020), by providing enhanced understanding of the dynamics of dust 568 emission surfaces (especially crust distribution and types). In terms of field-based 569 measurement of dust flux and/or emission potential of surfaces, von Holdt et al. (2017; 570 2019) demonstrated how the relatively high spatial resolution of Landsat data aided 571 the location of field campaigns to test emissions from different surfaces. The increased 572 space/time precision of source mapping offered by sensors like PlanetScope will be 573 invaluable for guiding field studies designed to quantify dust emission rates from 574 surface types within landscapes (King et al., 2011; Sweeney et al., 2011; Bryant, 2013; 575 Klose et al., 2019). Additional to the long term (multi-annual) monitoring of emission 576 surfaces, we note that the rapid delivery of PlanetScope data after collection, and the 
577 near real-time provision of imagery, will permit observation of dust events almost as 578 they unfold. Such a facility benefits field studies and other in situ observation 579 campaigns such as fixed-point air quality monitoring, and for purposes of fugitive dust 580 identification and wind erosion mitigation (e.g. Miller et al., 2012; Kandakji et al., 2020).

\subsection{Some limitations of CubeSat data for dust source observation}

583 In terms of their application to observing dust within source areas, some limitations of 584 CubeSat and the PlanetScope data used here specifically, require noting. Considering 585 the role of CubeSats for observing dynamic surface change phenomena, Cooley et al. 586 (2017) emphasise that constellation-derived imagery is acquired by way of smaller, 587 lower budget sensors such that radiometric quality, consistency and signal-to-noise 588 ratios are below that of missions supported by major space agencies. The large 589 number of individual platforms comprising any constellation unavoidably produces 590 inconsistency about cross-sensor calibration, image quality and accuracy of 591 geolocation, all of which represent general limitations. For PlanetScope geolocation 592 error is reported < $10 \mathrm{~m}$ (Planet Labs, 2020), but given the scale at which dust emission 593 can be considered, any such inaccuracy was effectively mitigated within the $100 \mathrm{~m}$ 594 grid source cell approach adopted here.

595 With the high albedo caused by often limited vegetation and typically light-coloured 596 sediments in dust source areas, many sources are characterised by bright surfaces 597 which can confound observation of plumes using only visible bands (Kaufman et al., 598 2002; Miller, 2003; Zhang et al., 2008). With only one non-visible band, opportunities 599 for algorithmic enhancement of dust in PlanetScope data are limited. While 600 recognising this issue, in this study we focused on interpretation of basic true-colour 601 scenes, and as we demonstrate, problems of plume definition are mitigated to some 602 extent by the excellent spatial resolution. CubeSat sensors may be especially prone 603 to signal saturation over bright surfaces, precluding plume detection in the worst 604 cases. This point, however, should be regarded next to the issue that dust detection 605 over bright surfaces can be problematic even for multi-spectral sensors such as 606 MODIS and SEVIRI (Baddock et al., 2009; Schepanski et al., 2009). 'Clear sky 
607 differencing', where dust-free images are subtracted to emphasise the presence of 608 dust has proven a fruitful approach (Murray et al., 2016). The regular repeat viewing 609 provided by CubeSats means that recent clean scenes required for background 610 subtraction should be readily available (Figure 3). This facilitates clear sky differencing 611 as a straightforward way to potentially enhance the appearance of dust plumes from 612 CubeSat imagery. The presence of cloud is a known complication for remote methods 613 of dust detection (Ackerman, 1997; Miller, 2003; Baddock et al., 2009), and the 614 absence of any inherent cloud masking processing for CubeSat data increases the 615 need for user interpretation of scenes (Cooley et al., 2017).

\section{CONCLUSION}

618 Advances in the spatial and temporal resolution of terrestrial remote sensing over 619 the past two decades have revealed the sources of aeolian dust with improving 620 spatial and temporal fidelity. Our case study suffices to show that the extreme spatial 621 detail, coupled with daily/sub-daily global coverage available from CubeSats such as 622 PlanetScope, provides a leap forward in our ability to monitor aeolian dust dynamics 623 through remote sensing. We offer a number of concluding remarks:

- We demonstrate the capabilities and potential benefits for understanding dust source behaviour achievable with highly-spatially-resolved imagery now readily available on a daily basis with global coverage.

- We show that the detail in which dust plumes can be captured with PlanetScope data now allows visualisation of dust emission at a scale which, for the first time, can realistically augment field measurements. The daily availability of data is comparable to moderate resolution sesors, but the opportunity for sub-daily constellation-based CubeSat imaging also provides considerable additional potential. Considering other remote sensing systems currently used for dust source observation, coupling CubeSat performance with hyper-temporal monitoring of dust source activity (e.g. via SEVIRI, 
635

636

637

638

639

640

641

642

643

644

645

646

647

648

649

650

651

652

653

654

655

656

657

658

659

660

661

662

663

664

665

666

667

GOES-16/17), will significantly enhance our ability to monitor and understand source dynamics.

- Taking advantage of its unprecedented detail and global coverage, we call for future, systematic evaluations of constellation-based, high spatial resolution imagery. These data provide a new impetus for informing our understanding of the spatio-temporal distribution of aeolian processes, the drivers of aeolian processes within the global dust cycle, and their representation in regional and global climate models.

\section{ACKNOWLEDGMENTS}

The authors acknowledge Planet Labs for their provision of free data access to education and research users. Mark Szegner at Loughborough helped with cartography, and we are grateful for the detailed comments of two reviewers and Editorial input. This work was inspired by a Royal Geographical Society (with the Institute of British Geographers) Small Research Grant (SRG 15/17) to MCB and NASA support (grant 80NSSC19K0195) to TEG.

\section{REFERENCES}

Ackerman, S.A., 1997. Remote sensing aerosols using satellite infrared observations. J. Geophys. Res. 102, 17069-17079.

Ashpole, I., Washington, R., 2013. A new high-resolution central and western Saharan summertime dust source map from automated satellite dust plume tracking. J. Geophys. Res. 118, 6981-6995.

Baddock, M.C., Bullard, J.E., Bryant, R.G., 2009. Dust source identification using MODIS: a comparison of techniques applied to the Lake Eyre Basin, Australia. Remote Sens. Environ. 113, 1511-1528.

Baddock, M.C., Gill, T.E., Bullard, J.E., Dominguez Acosta, M., Rivera Rivera, N.I., 2011. Geomorphology of the Chihuahuan Desert based on potential dust emissions. J. Maps 7, 249-259. 

of Australian dust: a case study of frontal winds and dust dynamics in the lower Lake Eyre Basin. Earth Surf. Process. Landf. 40, 982-1988.

Baddock, M.C., Ginoux, P., Bullard, J.E., Gill, T.E., 2016. Do MODIS-defined dust sources have a geomorphological signature? Geophys. Res. Lett. 43, 2606-2613.

Bakker, N.L., Drake, N.A., Bristow, C.S., 2019. Evaluating the relative importance of northern African mineral dust sources using remote sensing. Atmos. Chem. Phys. 19, 10525-10535.

Banks, J.R., Brindley, H.E., 2013. Evaluation of MSG-SEVIRI mineral dust retrieval products over North Africa and the Middle East. Remote Sens. Environ. 128, 58-73.

Bessho, K., Date, K., Hayashi, M., Ikeda, A., Imai, T., Inoue, H., Kumagai, Y., Miyakawa, T., Murata, H., Ohno, T. and Okuyama, A., 2016. An introduction to Himawari-8/9-Japan's new-generation geostationary meteorological satellites. J. Meteorol. Soc. Japan. Ser. II. 94, 151-183.

Brindley, H., Knippertz, P., Ryder, C., Ashpole, I., 2013. A critical evaluation of the ability of the Spinning Enhanced Visible and Infrared Imager (SEVIRI) thermal infrared red-green-blue rendering to identify dust events. Theoretical analysis. J Geophys. Res. 117, D07201.

Bryant, R.G., 2013. Recent advances in our understanding of dust source emission processes. Prog. Phys. Geogr. 37, 397-421.

Bryant, R.G., Bigg, G.R., Mahowald, N.M., Eckardt, F.D., Ross, S.G., 2007. Dust emission response to climate in southern Africa. J. Geophys. Res. 112, D09207.

Bullard, J., 2010. Bridging the gap between field data and global models: Current strategies in aeolian research. Earth Surf. Process. Landf., 35, 496-499.

Bullard, J., Baddock, M., McTainsh, G., Leys, J., 2008. Sub-basin scale dust source geomorphology detected using MODIS. Geophys. Res. Lett., 25, L15404.

Bullard, J.E., Harrison, S.P., Baddock, M.C., Drake, N., Gill, T.E., McTainsh, G., Sun, Y., 2011. Preferential dust sources: a geomorphological classification designed for use in global dust-cycle models. J. Geophys. Res. 116, F04034. 
708

709

710

711

712

713

714

715

716

717

718

719

720

721

722

723

724

725

726

727

728

729

730

731

732

733

734

735

736

737

738

739

740

741

742

743

744

745

746

747

Cahill, T.A., Gill, T.E., Reid, J.S., Gearhart, E.A., Gillette, D.A., 1996. Saltating particles, playa crusts and dust aerosols at Owens (dry) Lake, California. Earth Surf. Process. Landf. 21, 621-639.

Castiglia, P.J., Fawcett, P.J., 2006. Large Holocene lakes and climate change in the Chihuahuan Desert. Geology 34, 113-116.

Cooley, S.W., Smith, L.C., Stepan, L., Mascaro, J., 2017. Tracking dynamic northern surface water changes with high-frequency Planet CubeSat imagery. Remote Sens. 9, 1306.

Cui, M., Lu, H., Wiggs, G.F., Etyemezian, V., Sweeney, M.R., Xu, Z., 2019. Quantifying the effect of geomorphology on aeolian dust emission potential in northern China. Earth Surf. Process. Landf. 44, 2872-2884.

d'Angelo, P., Máttyus, G., Reinartz, P., 2016. Skybox image and video product evaluation. Int. J. Image Data Fus., 7, 3-18.

da Silva Curiel, A., Boland, L., Cooksley, J., Bekhti, M., Stephens, P., Sun, W., Sweeting, M., 2005. First results from the disaster monitoring constellation (DMC). Acta Astronaut. 56, 261-271.

Dominguez Acosta, M., 2009. The Pluvial Lake Palomas-Samalyuca Dunes System. Ph.D. Dissertation (Geological Sciences), University of Texas at El Paso.

Eckardt, F.D., Kuring, N., 2005. SeaWiFS identifies dust sources in the Namib Desert. Int. J. Rem. Sens. 26, 4159-4167.

Field, J.P., Breshears, D.D., Whicker, J.J., 2009. Toward a more holistic perspective of soil erosion: Why aeolian research needs to explicitly consider fluvial processes and interactions. Aeolian Res. 1, 9-17.

Floyd, K.W., Gill, T.E., 2011. The association of land cover with aeolian sediment production at Jornada Basin, New Mexico, USA. Aeolian Res. 3, 55-66.

Gasch, P., Rieger, D., Walter, C., Khain, P., Levi, Y., Knippertz, P., Vogel, B., 2017. Revealing the meteorological drivers of the September 2015 severe dust event in the Eastern Mediterranean. Atmos. Chem. Phys. 17, 13573-13604. 
748 Gill, T.E., 1996. Eolian sediments generated by anthropogenic disturbance of playas:

749 human impacts on the geomorphic system and geomorphic impacts on the human

750 system. Geomorphology 17, 207-228.

751

752 Gillette, D.A., 1999. A qualitative geophysical explanation for hot spot dust emitting

753

754

755

756

757

758

759

760

761

762

763

764

765

766

767

768

769

770

771

772 source regions. Contrib. Atmos. Phys. 72 (1), 67-78.

Ginoux, P., Garbuzov, D., Hsu, N.C., 2010. Identification of anthropogenic and natural dust sources using Moderate Resolution Imaging Spectroradiometer (MODIS) Deep Blue level 2 data, J. Geophys. Res., 115, D05204.

Ginoux, P., Prospero, J.M., Gill, T.E., Hsu, N.C., Zhao, M., 2012. Global-scale attribution of anthropogenic and natural dust sources and their emission rates based on MODIS Deep Blue aerosol products. Rev. Geophys. 50, RG3005.

Hahnenberger, M., Nicoll, K., 2014, Geomorphic and land cover identification of dust sources in the eastern Great Basin of Utah, USA. Geomorphology, 204, 657-672.

Haustein, K., Washington, R., King, J., Wiggs, G., Thomas, D.S.G., Eckardt, F.D., Bryant, R.G., Menut, L., 2015. Testing the performance of state-of-the-art dust emission schemes using DO4Models field data. Geosci. Model Dev. 8, 341-362.

Heinold, B., Tegen, I., Schepanski, K., Banks, J.R., 2016. New developments in the representation of Saharan dust sources in the aerosol-climate model ECHAM6-

773

774 HAM2. Geosci. Model Dev. 9, 765-777.

775

Hennen, M., White, K. Shahgedanova, M., 2019. An assessment of SEVIRI imagery

776 at various temporal resolutions and the effect on accurate dust emission mapping.

777

778 Remote Sens.11, 918.

779

Hsu, N.C., Jeon, M.-J., Bettenhausen, C., Sayer, A.M., Hansell, R., Seftor, C.S.,

780

781

782

783 Huang, J., Tsay, S.-C., 2013. Enhanced Deep Blue aerosol retrieval algorithm: The second generation: J Geophys. Res. 118, 9296-9315.

784

785

INEGI (Instituto Nacional de Estadística, Geografía y Informática), México, 2001. Sistema de Topoformas. Available online at http://en.www.inegi.org.mx/temas/fisiografia/default.html\#Downloads Accessed 25th 786 
787 Kandakji, T., Gill, T.E., Lee, J.A., 2020. Identifying and characterizing dust point 788 sources in the southwestern United States using remote sensing and GIS. 789 Geomorphology 353, 107019.

790

Kaufman, Y.J., Tanré, D., Boucher, O., 2002. A satellite view of aerosols in the climate 792

King, J., Etyemezian, V., Sweeney, M., Buck, B.J., Nikolich, G., 2011. Dust emission variability at the Salton Sea, California, USA. Aeolian Res. 3, 67-79.

Klose, M., Gill, T.E., Etyemezian, V., Nikolich, G., Zadeh, Z.G., Webb, N.P., Van Pelt, R.S., 2019. Dust emission from crusted surfaces: insights from field measurements and modelling. Aeolian Res. 40, 1-14.

Kocurek, G., Lancaster, N., 1999. Aeolian system sediment state: Theory and Mojave Desert Kelso dune field example. Sedimentology, 46, 505-515.

Kok, J.F., Mahowald, N.M., Albani, S., Fratini, G., Gillies, J.A., Ishizuka, M., Leys, J.F., Mikami, M., Park, M.S., Park, S.U., Van Pelt, R.S., 2014. An improved dust emission model with insights into the global dust cycle's climate sensitivity. Atmos. Chem. Phys. $14,13023-13041$.

Kondragunta, S., Zhang, H., Ciren, P., Laszlo, I., Tong, D., 2018. Tracking Dust Storms Using the Latest Satellite Technology: The Rapid Refresh GOES-16 Advanced Baseline Imager. EM: Mag. Env. Manag. (Air Waste Manag. Assoc.), May 2018, 25-30.

Kopacz, J.R., Herschitz, R., Roney, J., 2020. Small satellites: an overview and assessment. Acta Astronaut. 170, 93-105.

Lancaster, N., Baas, A., 1998. Influence of vegetation cover on sand transport by wind: field studies at Owens Lake, California. Earth Surf. Proc. Landf. 23, 69-82.

Lee, J.A., Gill, T.E., Mulligan, K.R., Dominguez Acosta, M., Perez, A.E., 2009. Land use/land cover and point sources of the 15 December 2003 dust storm in southwestern North America. Geomorphology 105, 18-27.

Lee, J.A., Baddock, M.C., Mbuh, M.J., Gill, T.E., 2012. Geomorphic and land cover characteristics of aeolian dust sources in west Texas and eastern New Mexico, USA. Aeolian Res. 3, 459-466. 
Li, J., Roy, D.P., 2017. A global analysis of Sentinel-2A, Sentinel-2B and Landsat-8 data revisit intervals and implications for terrestrial monitoring. Remote Sens. 9, 902. Blowing dust and highway safety in the southwestern United States: characteristics of dust emission "hotspots" and management implications. Sci. Total Environ. 621, 1023-1032.

Liu, S., Hodgson, M.E., 2016. Satellite image collection modeling for large area hazard emergency response. ISPRS J. Photogramm. Remote Sens. 118, 13-21.

Mahowald, N.M., Bryant, R.G., del Corral, J., Steinberger, L., 2003. Ephemeral lakes and desert dust sources. Geophys. Res. Lett. 30, 1074.

Mahowald, N.M., Kloster, S., Engelstaedter, S., Moore, J.K., Mukhopadhyay, S., McConnell, J.R., Albani, S., Doney, S.C., Bhattacharya, A., Curran, M.A.J., Flanner, M.G., Hoffman, F.M., Lawrence, D.M., Lindsay, K., Mayewski, P.A., Neff, J., Rothenberg, D., Thomas, E., Thornton, P.E., Zender, C.S., 2010. Observed 20th century desert dust variability: Impact on climate and biogeochemistry. Atmos. Chem. Phys. 10, 10875-10893.

Miller, S.D., 2003. A consolidated technique for enhancing desert dust storms with

Miller, M.E., Bowker, M.A., Reynolds, R.L., Goldstein, H.L., 2012. Post-fire land 854 treatments and wind erosion - Lessons from the Milford Flat Fire, UT, USA. Aeolian Res. 7, 29-44. aeolian mineral dust: present and past. In: Stuut, J.-B., Knippertz P. (Eds.), Mineral dust - a key player in the Earth system. Springer, Berlin. pp. 51-74.

Murray, J.E., Brindley, H.E., Bryant, R.G., Russell, J.E., Jenkins, K.F., Washington, R., 2016. Enhancing weak transient signals in SEVIRI false color imagery: application 863

864 Novlan, D.J., Hardiman, M., Gill, T.E., 2007. A synoptic climatology of blowing dust 865 events in El Paso, Texas from 1932-2005. Preprints, 16th Conf. on Applied Climatology, Amer. Meteorol. Soc., J3.12. 
Nicoll, K., Hahnenberger, M., Goldstein, H.L., 2020. 'Dust in the wind' from source-tosink: Analysis of the 14-15 April 2015 storm in Utah. Aeolian Res. 46, 100532.

O'Loingsigh, T., McTainsh, G.H., Tapper, N.J., Shinkfield, P., 2010. Lost in code: a critical analysis of using meteorological data for wind erosion monitoring. Aeolian Res. 2, 49-57.

874

O'Loingsigh, T., Mitchell, R.M., Campbell, S.K., Drake, N.A., McTainsh, G.H., Tapper, N.J., Dunkerley, D.L., 2015. Correction of dust event frequency from MODIS QuickLook imagery using in-situ aerosol measurements over the Lake Eyre Basin, Australia. Rem. Sens. Environ. 169, 222-231.

Parajuli, S.P., Zender, C.S., 2017, Connecting geomorphology to dust emission through high-resolution mapping of global land cover and sediment supply. Aeolian Res. 27, 47-65.

Parajuli, S.P., Yang, Z.L., Kocurek, G., 2014, Mapping erodibility in dust source regions based on geomorphology, meteorology, and remote sensing. J. Geophys. Res. 119, 1977-1994.

Planet Labs, 2020. Imagery and Archive details, available at: 894

Park, S.H., Jung, H.S., Lee, M.J., Lee, W.J., Choi, M.J., 2019. Oil Spill Detection from PlanetScope Satellite Image: Application to Oil Spill Accident near Ras Al Zour Area, Kuwait in August 2017. J. Coastal Res. Supp. 90, 251-260. https://www.planet.com/products/planet-imagery/ [Accessed $1^{\text {st }}$ June 2020]

904 Reynolds, R.L., Yount, J.C., Reheis, M., Goldstein, H., Chavez, P. Jr., Fulton, R., 905 Whitney, J., Fuller, C., Forester, R.M., 2007. Dust emission from wet and dry playas 906 in the Mojave Desert, USA. Earth Surf. Proc. Landf. 32, 1811 - 1827. 
908 Richter, D., Gill, T., 2018. Challenges and opportunities in atmospheric dust emission,

Rivas, J.A. Jr., Schröder, T., Gill, T.E., Wallace, R.L., Walsh, E.J., 2019. Anemochory of diapausing stages of microinvertebrates in North American drylands. Freshwater Biol. 64, 1303-1314.

Rivera Rivera, N.I., Gill, T.E., Gebhart, K.A., Hand, J.L., Bleiweiss, M.P., Fitzgerald, R.M., 2009. Wind modeling of Chihuahuan Desert dust events. Atmos. Environ. 43, 347-354.

Rivera Rivera, N.I., Gill, T.E., Bleiweiss, M.P., Hand, J.L., 2010. Source characteristics of hazardous Chihuahuan Desert dust outbreaks. Atmos. Environ. 44, 2457-2468.

Rosen, M.R. 1994. The importance of groundwater in playas: a review of playa classifications and the sedimentology and hydrology of playas. Geol. Soc. Amer. Spec. Pap. 289, 1-18.

Schepanksi, K., Tegen, I., Laurent, B., Heinold, B., Macke A., 2007. A new Saharan dust source activation frequency map derived from MSG-SEVIRI IR-channels. Geophys. Res. Lett., 34, L18803.

Schepanski, K., Tegen, I., Todd, M. C., Heinold, B., Bönisch, G., Laurent, B., Macke, A., 2009. Meteorological processes forcing Saharan dust emission inferred from MSGSEVIRI observations of subdaily dust source activation and numerical models. J. Geophys. Res. 114, D10201.

Schepanski, K., Tegen, I., Macke, A., 2012. Comparison of satellite based observations of Saharan dust source areas. Remote Sens. Environ. 123, 90-97. An introduction to Meteosat second generation (MSG). Bull. Am. Meteorol. Soc. 83, 977-992.

Shao, Y., Wyrwoll, K.H., Chappell, A., Huang, J., Lin, Z., McTainsh, G.H., Mikami, M., Tanaka, T.Y., Wang, X., Yoon, S., 2011. Dust cycle: An emerging core theme in Earth system science. Aeolian Res. 2, 181-204. 
946 Sinclair, S.N., LeGrand, S.L., 2019. Reproducibility assessment and uncertainty 947 quantification in subjective dust source mapping. Aeolian Res. 40, 42-52.

948

949 She, L., Xue, Y., Yang, X., Guang, J., Li, Y., Che, Y., Fan, C., Xie, Y., 2018, Dust 950 detection and intensity estimation using Himawari-8/AHI observation. Remote Sens., 951 10, 490.

952

Sowden, M., Mueller, U., Blake, D., 2018, Review of surface particulate monitoring of 954 dust events using geostationary satellite remote sensing. Atmos. Environ. 183, 154164.

Sweeney, M.R., McDonald, E.V., Etyemezian, V., 2011, Quantifying dust emissions 959 from desert landforms, eastern Mojave Desert, USA. Geomorphology 135, 21-34.

Thompson, D., Braverman, A., Brodrick, P.G., Candela, A., Carmon, N., Clark, R.N., 965 Connely, D., Green, R.O., Kokaly, R.F., Li, L., Mahowald, N., Miller, R.L., Oking, G.S., Painter, T.H., Swayze, G.A., Turmon, M., Susilouto, J., Wettergreen, D.S., 2020. Quantifying uncertainty for remote spectroscopy of surface composition. Remote Sens. Environ. 247, 111898.

Urban, F.E., Goldstein, H.L., Fulton, R., Reynolds, R.L. (2018) Unseen dust emission and global dust abundance: documenting dust emission from the Mojave Desert (USA) by daily remote camera imagery and wind-erosion measurements. J. Geophys. Res. 123, 8735-8753. frequency inventory for southern Africa, 2005-2008. Geophys. Res. Lett. 40, 52745279 . emission dynamics at the landform scale. Remote Sens. Environ. 198, 229-243. landscape dust emission potential using combined ground-based measurements and remote sensing data. J. Geophys. Res. 124, 1080-1098. 
986 Villela, T., Costa, C.A., Brandão, A.M., Bueno, F.T., Leonardi, R., 2019. Towards the 987 thousandth CubeSat: A statistical overview. Int. J. Aerospace Eng. 2019, 063145.

Walker, A.L., Liu, M., Miller, S.D., Richardson, K.A., Westphal, D.L., 2009. 990 Development of a dust source database for mesoscale forecasting in Southwest Asia. J. Geophys. Res. 114, D18207.

Washington, R., Todd, M., Middleton, N.J., Goudie, A.S., 2003. Dust storm source 994 areas determined by the Total Ozone Monitoring Spectrometer and surface observations. Ann. Assoc. Am. Geog. 93, 297-313.

Webb, N.P., Strong, C.L., 2011. Soil erodibility dynamics and its representation for 999 wind erosion and dust emission models. Aeolian Res. 3, 165-179.

Webb, N.P., Herrick, J.E., Van Zee, J.W., Courtright, E.M., Hugenholtz, C.H., Zobeck, 1002 T.M., Okin, G.S., Clingan, S.D., Cooper, B.F., Billings, B.J, Boyd, R., Duniway, M.C., Derner, J.D., Fox, F.A., Havstad, K.M., Heilman, P., Ludwig, N.A., Metz, L.J., Nearing, M.A., Norfleet, M.L., Pierson, F.B., Sanderson, M.A., Sharratt, B.S., Steiner, J.L., Tatarko, J., Tedela, N.H., Toledo, D., Unnasch, R.S., Van Pelt, R.S., Wagner, L., 2016. The National Wind Erosion Research Network: building a standardized longterm data resource for aeolian research, modeling and land management. Aeolian

Webb, N.P., Chappell, A., Edwards, B.L., McCord, S.E., Van Zee, J.W., Cooper, B.F., 1010 Courtright, E.M., Duniway, M.C., Sharratt, B., Tedela, N., Toledo, D., 2019. Reducing sampling uncertainty in aeolian research to improve change detection. J. Geophys. Res. 124, 1366-1377.

Wicaksono, P., Lazuardi, W., 2018. Assessment of PlanetScope images for benthic habitat and seagrass species mapping in a complex optically shallow water environment. Intl. J. Remote Sens. 39, 5739-5765.

1024

Yue, H., He, C., Zhao, Y., Ma, Q., Zhang, Q., 2017. The brightness temperature adjusted dust index: An improved approach to detect dust storms using MODIS imagery. Int. J. Appl. Earth Obs. Geoinf. 57, 166-176.

Zender, C.S., Newman, D.J., Torres, O., 2003. Spatial heteorogeneity in aeolian erodibility: Uniform, topographic, geomorphic and hydrologic hypotheses. J. Geophys. Res. 108, 4543. 
1026 Zhang, B., Tsunekawa, A., Tsubo, M., 2008. Contributions of sandy lands and stony 1027 deserts to long-distance dust emission in China and Mongolia during 2000-2006. 1028 Global Planet. Change 60, 487-504. 
1029

\section{FIGURES}

1030 a)

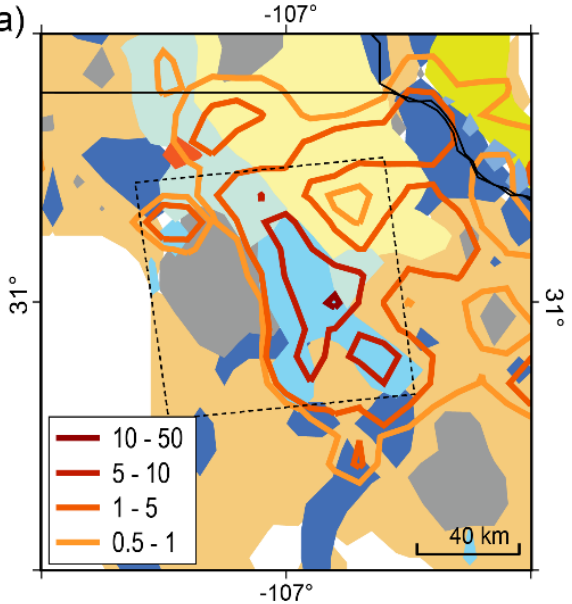

b)

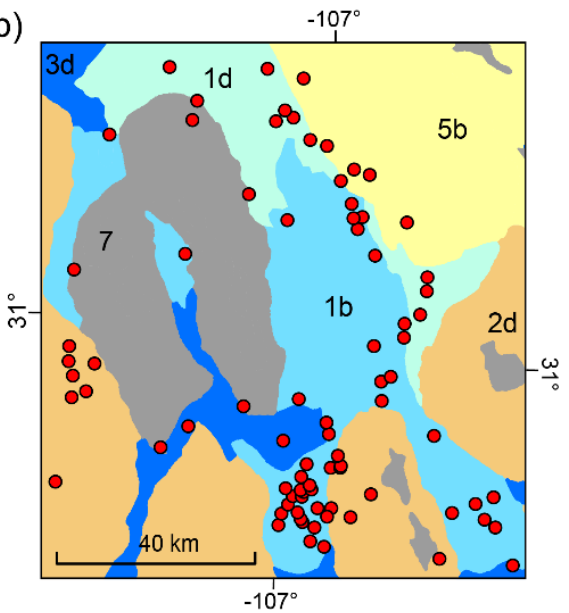

c)



1032 Figure 1: Assessments of dust source activity in the northern Chihuahuan Desert, 1033 based on different moderate resolution MODIS data. a) Contours showing long term 1034 (2003-2014) dust loading as represented by Frequency of Occurrence (FoO \% days) 
1035 for MODIS Dust Optical Depth $>0.75$ (after Baddock et al., 2016), superimposed on 1036 the preferential dust source (PDS) geomorphological classification of emission 1037 potential (Bullard et al., 2011). Dashed box indicates focus of panels (b) and (c). b) 1038 Inventory of dust plume origin points 2001-2009 for the study region, as derived from 1039 inspection of true-colour MODIS scenes (Baddock et al., 2011), superimposed on 1040 the same PDS geomorphological classification (1b - ephemeral lake, 1d - dry, non1041 consolidated lake, 2d - high relief (unarmoured, unincised) alluvial systems, 3d 1042 low relief (unarmoured, unincised) alluvial systems, 5b - aeolian sand dunes, 7 low 1043 emission surfaces) c) Example true-colour MODIS dust scene of a regional emission 1044 event (27th November 2005) with plume origins marked. The extent of the Bolson de 1045 los Muertos playa is shown, with the blue crosshatch indicating the Rio Santa Maria 1046 paleo-delta feeding into the playa. Dashed box indicates focus of Figure 2(c,d) in the 1047 southwestern arm of the playa.

1048

1049

1050

1051

1052

1053

1054

1055

1056 

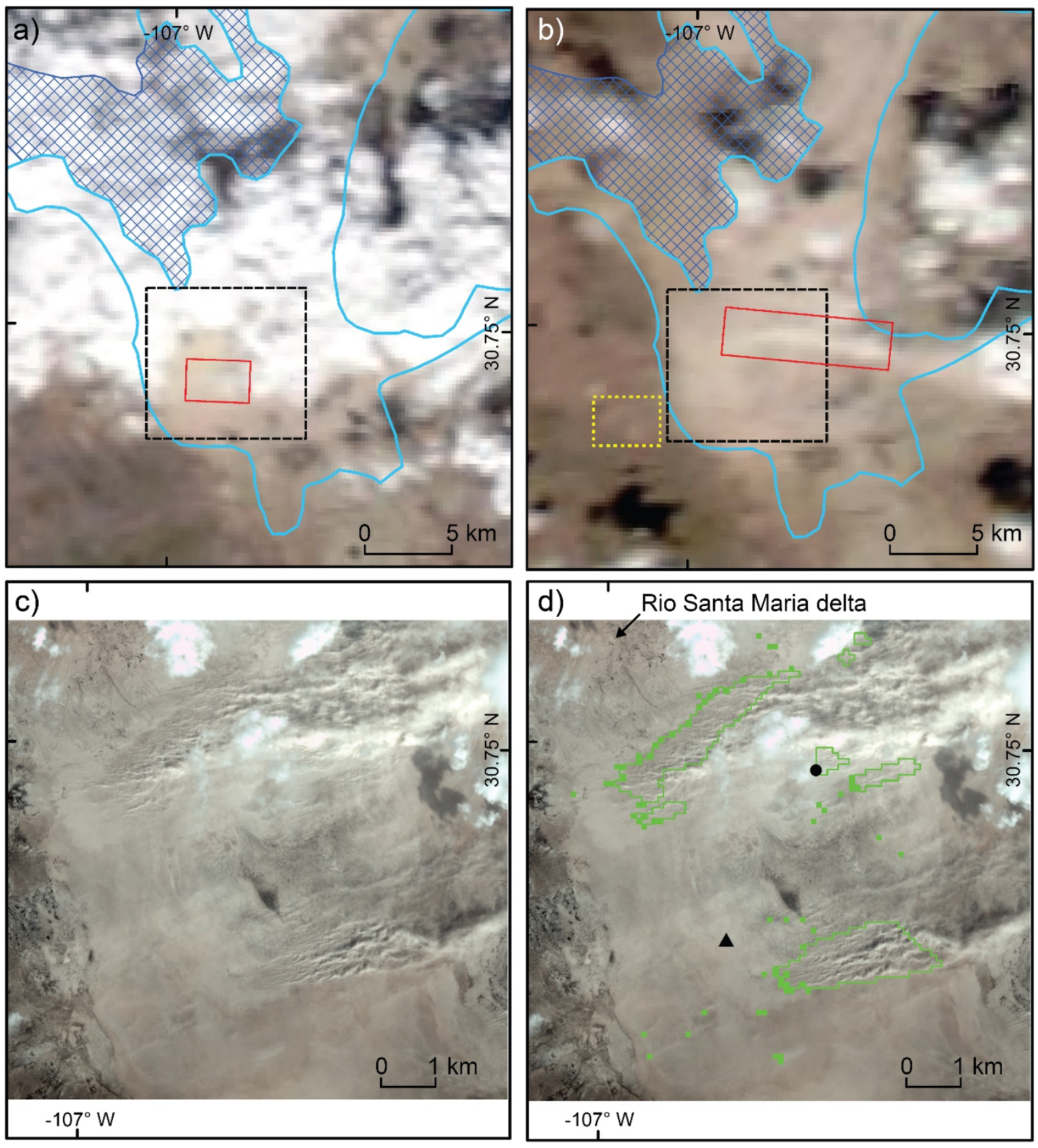

1058 Figure 2 a) Terra MODIS (1735 UTC) true-colour scene of 30th November 2018 dust
1059 event showing the faint presence of dust visible on the south-western lobe of the of 1060 Bolson de los Muertos playa. Red box highlights the plume over the playa surface, 1061 before presence of cloud to the east obscures plume. Plume interpreted with a 1062 comparison to dust-free MODIS scene (not shown). Hashed lines show extent of the 1063 Rio Santa Maria paleo-delta from INEGI (2001) national soil map. Pixel resolution 250 $1064 \mathrm{~m}$. Dashed black box shows focus of figure panels (c) and (d). b) Aqua MODIS (2050 
1065 UTC) from the same day showing presence of a more apparent dust plume slightly 1066 further to the north in the focus area. Red box highlights plume extending to the east. 1067 Dashed yellow box shows focus of Figure 5. c) PlanetScope (1706 UTC) true colour 1068 scene of 30th November 2018 dust event, showing emission occurring in the south1069 western arm of Bolson de los Muertos playa. Pixel resolution $3 \mathrm{~m}$. Note some cloud is 1070 present, but less than shown in MODIS at 1735 UTC. (A high resolution version of this 1071 panel is available in the Supplementary Material.) d) Grid cells where surface emission 1072 can be estimated from plumes identifiable in PlanetScope, for a regular $100 \times 100 \mathrm{~m}$ 1073 grid over the southwest arm of the Bolson de los Muertos. Solid cells - cells containing 1074 discernible upwind initiation points of small plumes shown in (c). Open cells - cells 1075 with evidence of likely emission from the surface, shown by multiple individual small 1076 scale plumes, close to the surface, and located downwind of solid cells containing 1077 discernible initiation. Black triangle and circle indicate apparent plume source 1078 estimated from Terra and Aqua images $(a, b)$ respectively.

1079

1080

1081

1082

1083

1084 


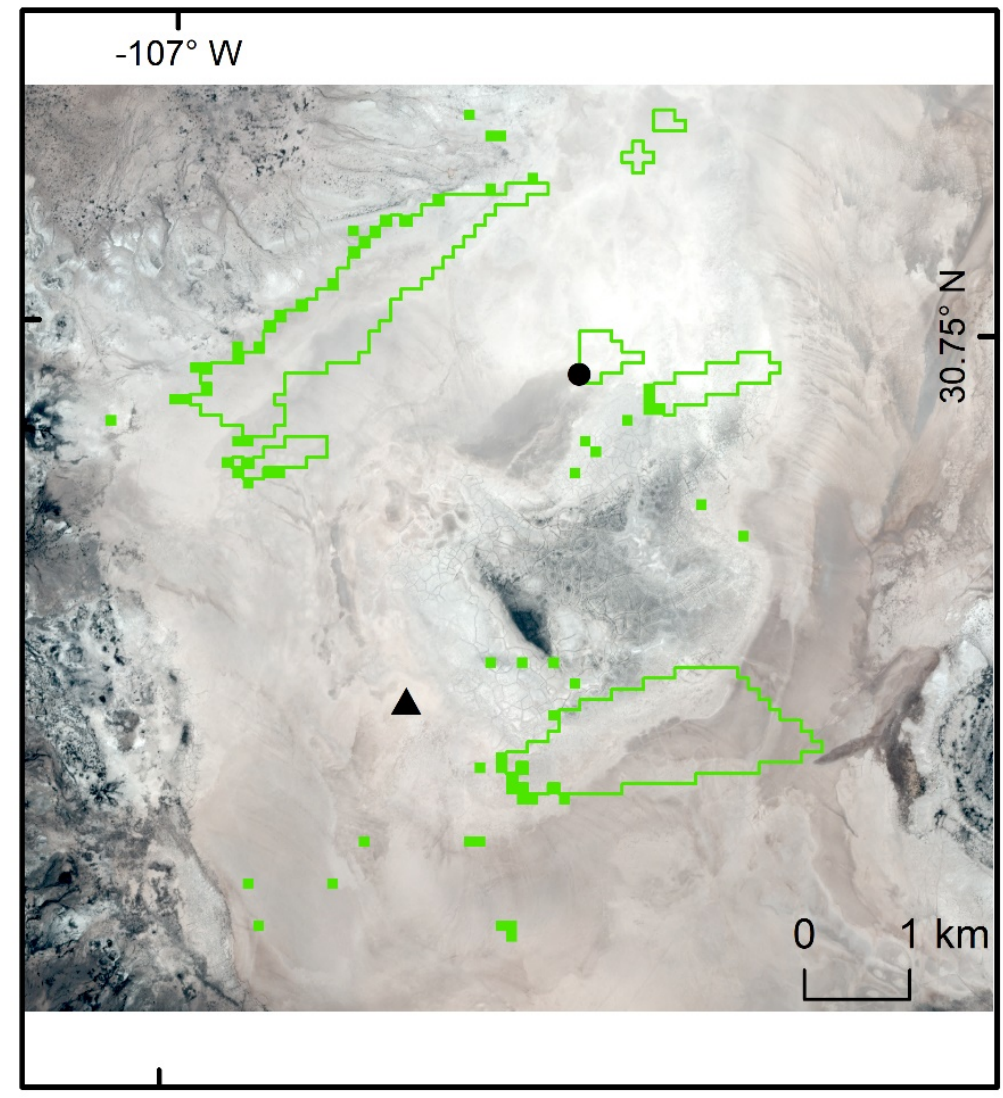

1086 Figure 3: True colour PlanetScope scene (27th November 2018, 1722 UTC) depicting 1087 focus section of the southwest arm of the Bolson de los Muertos playa surface three 1088 days before the dust event in Figure 2. Solid squares are the upwind emitting grid 1089 cells, open green polygons are the broader downwind estimates of emitting surface 1090 from Figure 2d.

1091

1092 


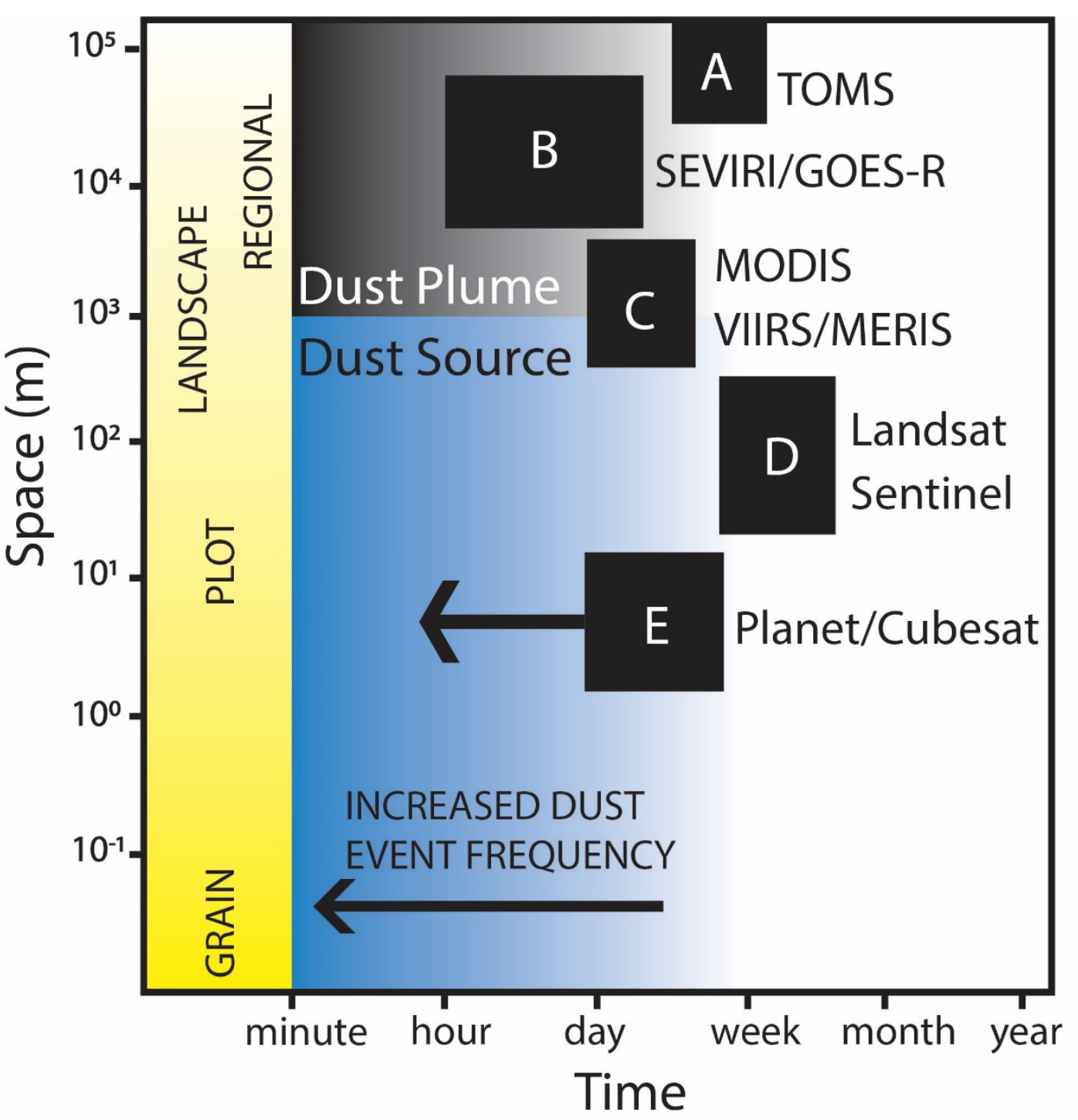

1100 Figure 4: Conceptual figure characterising time and spatial scales of dust emission 1101 and dust transport (i.e. plume passage) phenomena, in relation to the 1102 monitoring/detection capabilities of existing satellite systems, and the niche of 1103 CubeSats (e.g. PlanetScope), from this study. We use the spatial scale limits 1104 suggested by Strong and Webb (2011) to highlight that the spatial resolution, in which 1105 most remote sensing observations operate, obviates plot-scale of understanding dust 1106 emission processes. In the temporal, most studies are unable to sample at a scale 1107 where a representative sample of dust events will be captured, compared to field1108 based (e.g. Klose et al., 2019) or meteorological data-based (e.g. O'Loingsigh et al., 1109 2010) approaches. Black boxes represent realistic limits in dust source/plume 1110 detection based upon published studies (A: TOMS, Bryant et al., 2007; B: SEVIRI, 
1111 Murray et al. 2016; C: MODIS, Baddock et al., 2009; D: Landsat/Sentinel, von Holdt 1112 et al., 2017; Bakker et al., 2019, E: CubeSat/PlanetScope; this study.)

1113

1114

1115

1116

1117

1118

1119

1120

1121

1122

1123

1124 


1126 Figure 5: PlanetScope overpasses available 11 minutes apart, achieved by the Planet 1127 CubeSat constellation for the 30th November 2018 regional dust event. The image 1128 sequence helps constrain the spatial occurrence and temporal onset of dust emission 1129 from centre-pivot irrigated field systems during the day's dust event. A 1003 MST 1130 (1703 UTC) overpass was also available for this site. Area of focus is shown by yellow 1131 box in Figure $2 b$.

1132

1133 
1134 Supplementary material

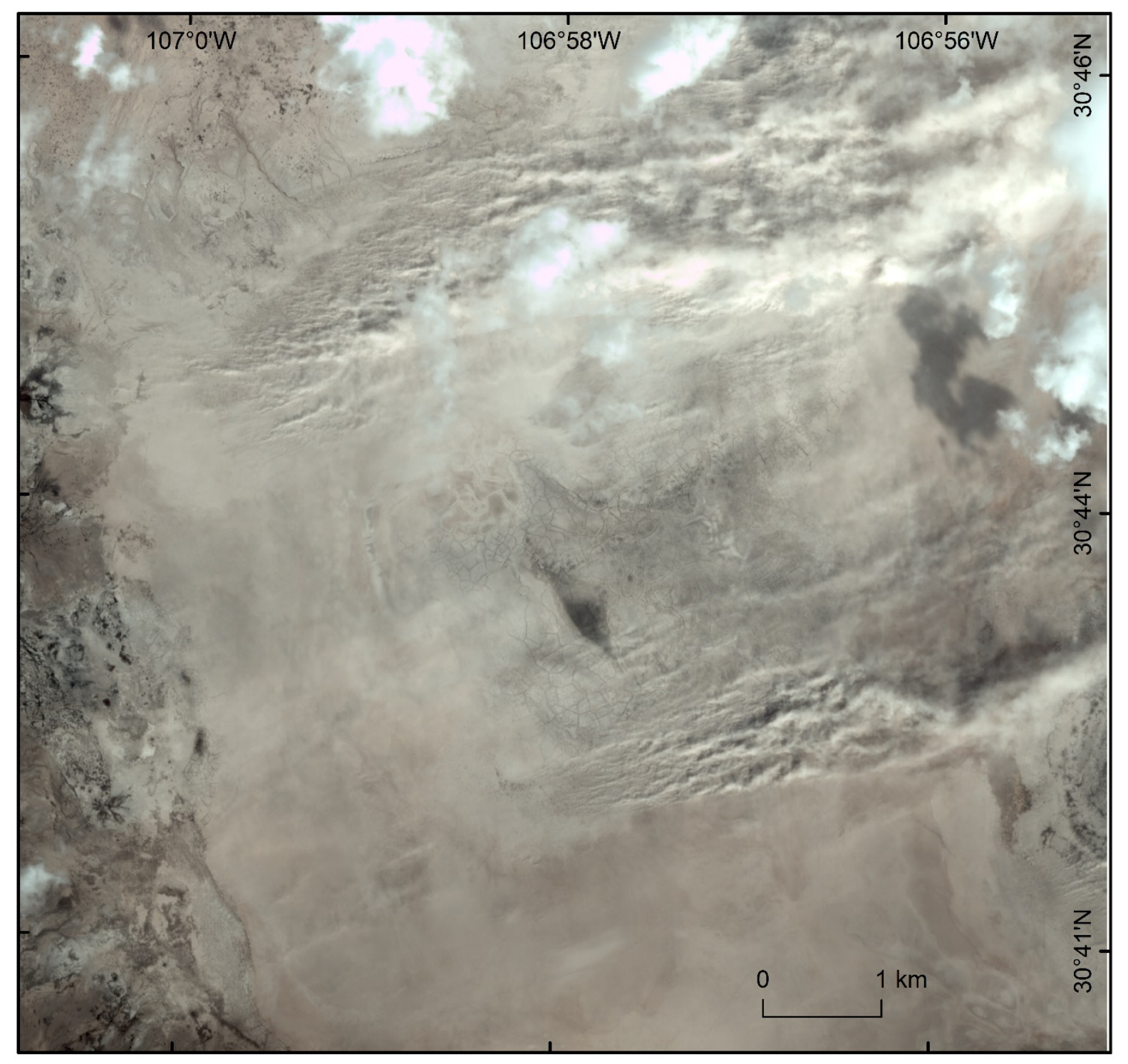

1135 